\title{
Épocas de semeadura do milho com menor risco de ocorrência de deficiência hídrica no município de Santa Maria, RS, Brasil ${ }^{1}$
}

\author{
Sowing dates of corn with lower risk of water defifcit in Santa Maria, RS, Brazil
}

\author{
Astor Henrique Nied ${ }^{2}$ Arno Bernardo Heldwein ${ }^{3}$ Valduino Estefanel ${ }^{4}$ \\ Joel Cordeiro da Silva ${ }^{5}$ Cleber Maus Alberto ${ }^{5}$
}

\section{RESUMO}

Neste trabalho, objetivou-se determinar as épocas de semeadura (ES) com menor e maior risco de deficiência hídrica para a cultura do milho no município de Santa Maria (RS). Para isso, utilizaram-se 34 anos de dados, coletados na estação meteorológica de Santa Maria, no cálculo do balanço hídrico (BH) seqüencial diário, com base no modelo de Thornthwaite e Mather adaptado. Simularam-se 42 ES, de agosto a fevereiro, para os três grupos de maturação de variedades da cultura. A duração dos subperíodos e do ciclo foi estimada a partir da soma térmica efetiva com temperatura base de $10^{\circ} \mathrm{C}$. Foi realizado o $\mathrm{BH}$ considerando-se a fração de água disponível no solo, abaixo da qual iniciam as deficiências hídricas. A evapotranspiração de referência (ETo) foi estimada pelo método de Penman. Verificou-se que nas épocas de semeadura de outubro e novembro e na primeira quinzena de dezembro, as probabilidades de ocorrência de deficiência hídrica são maiores no total do ciclo. As épocas de semeadura de dezembro ao início de janeiro apresentam os menores riscos de deficiência hídrica no período mais crítico para a cultura. Nestas ES, no entanto, deve-se efetivar a semeadura somente se houver condição de umidade no solo adequada para a germinação e emergência.

Palavras-chave: Zea mays L., balanço hídrico, estresse hídrico.

\section{ABSTRACT}

The aim of this work was to determine the corn sowing date (ES) with the least and the highest risk of water deficit in Santa Maria, RS, Brazil. Daily data during 34 years collected at a meteorological station in Santa Maria were used to calculate the daily water balance (BH), based on the Thornthwaite and Mather adapted model. Forty two ES were simulated, from August to February, for three corn maturation groups. The duration of the subperiods and cycle was estimated by residual growing degreedays with $10^{\circ} \mathrm{C}$ as base temperature for development. The $\mathrm{BH}$ was calculated considering the fraction of available water in the soil, a threshold below which water deficit starts. Reference evapotranspiration (ETo) was estimated with the adjusted Penman model. It was concluded that the water deficiency occurrence probability are great in October, November and the first half of December sowing dates, considering all the crop cycle. December and the beginning January sowing dates present the least risk of water stress during the most critic period, assuming enough soil moisture at sowing and emergence.

Key words: Zea mays L., water balance, water stress.

\section{INTRODUÇÃO}

A disponibilidade hídrica é o fator mais importante para a expressão do rendimento potencial de uma cultura. Um dos indicadores utilizados para quantificá-la é a evapotranspiração relativa, definida como a relação entre a evapotranspiração real (ETr), decorrente da disponibilidade hídrica existente, e a evapotranspiração máxima (ETm) da cultura em cada subperíodo de desenvolvimento. Através dessa relação, é possível explicar o rendimento relativo de uma cultura (JENSEN, 1968). Nesse sentido, sob condições de campo no Rio Grande do Sul, destacam-

\footnotetext{
${ }^{1}$ Parte da dissertação de mestrado do primeiro autor. Programa de Pós-graduação em Agronomia-UFSM. Nied, bolsista da Coordenação de Aperfeiçoamento de Pessoal de Nível Superior (CAPES). Heldwein, bolsista do Conselho Nacional de Desenvolvimento Científico e Tecnológico (CNPq)

${ }^{2}$ Programa de Pós-graduação em Agronomia, Universidade Federal de Santa Maria (UFSM), Santa Maria, RS, Brasil. E-mail: tornied@yahoo.com.br

${ }^{3}$ Departamento de Fitotecnia, Universidade Federal de Santa Maria, 97105-900, Santa Maria, RS, Brasil. E-mail: heldwein@ccr.ufsm.br ${ }^{4}$ Centro Universitário Franciscano de Santa Maria, Santa Maria, RS, Brasil.

${ }^{5}$ Programa de Pós-graduação em Engenharia Agrícola da UFSM, Santa Maria, RS, Brasil.
} 
se os trabalhos para a cultura da soja (BERLATO, 1987), girassol (BARNI et al., 1996) e milho (MATZENAUER et al., 1995, FERRAUDO et al., 1995).

O milho é uma cultura de grande exigência hídrica, a qual é uma função dos elementos meteorológicos e da cultura, principalmente do seu índice de área foliar (IAF), pois o coeficiente de cultura é uma função do $I A F$. Portanto, ao longo do seu crescimento e desenvolvimento, geralmente a maior exigência hídrica coincide com o subperíodo, denominado crítico, em que a deficiência hídrica mais afeta o rendimento. Este subperíodo está compreendido entre a antese e a maturação leitosa, no qual o $I A F$ se mantém próximo do máximo. Nesse subperíodo, MATZENAUER et al. (2002) observaram valores médios de ETm de $6,6 \mathrm{~mm} \mathrm{dia}^{-1}$, e no ciclo, 4,6 mm dia ${ }^{-1}$, totalizando 572mm. CASEIRO et al. (1997) encontraram valores de ETm médio e máximo diários e acumulados no ciclo do milho de, respectivamente, $5,17,7,17$ e $668 \mathrm{~mm}$. RADIN et al. (2000) verificaram valores extremos de até $11,0 \mathrm{~mm} \mathrm{dia}^{-1}$ após a antese da cultura, enquanto KANG et al. (2003) obtiveram valores médios diários em torno de 5,3mm dia ${ }^{-1}$ aos 75 dias após a semeadura.

A precipitação normal do Rio Grande do Sul é bem distribuída ao longo do ano: $24 \%$ no verão, $25 \%$ no outono, $25 \%$ no inverno e $26 \%$ na primavera (MORENO, 1961). No entanto, nos meses de verão, devido à maior demanda evaporativa da atmosfera, freqüentemente as chuvas não são suficientes para suprir as necessidades das culturas. Além da variabilidade anual da distribuição da precipitação e ao longo de um ano agrícola, nos meses de verão, essas apresentam maior variabilidade espacial e, freqüentemente, têm alta intensidade. Segundo BERLATO \& FONTANA (2003), a precipitação e a conseqüente disponibilidade hídrica no período de dezembro a março explica 79\% da variação interanual dos rendimentos da soja no Rio Grande do Sul.

A evapotranspiração relativa é uma variável importante para indicar as variações de rendimento de grãos da cultura do milho para diferentes épocas de semeadura, anos e locais do Rio Grande do Sul (MATZENAUER et al., 1995). Assim como BERGAMASCHI et al. (1999), esses autores também observaram que o subperíodo de maior sensibilidade dessa cultura à deficiência hídrica é o que ocorre do início da antese ao início do enchimento de grãos.

Para o município de Santa Maria, situado na região fisiográfica da Depressão Central do Rio Grande do Sul, a cultura do milho tem grande importância econômica e social e, especialmente, na alimentação animal.
O objetivo deste trabalho foi determinar as épocas de semeadura da cultura do milho que apresentam menores riscos de ocorrer deficiência hídrica para a região de Santa Maria.

\section{MATERIAL E MÉTODOS}

Os dados meteorológicos foram coletados na Estação Meteorológica de Santa Maria, instalada na área experimental do Departamento de Fitotecnia da Universidade Federal de Santa Maria (latitude: $29^{\circ}$ 43'S, longitude: 53 43'W e altitude: $95 \mathrm{~m}$ ). A estação meteorológica de Santa Maria foi instalada em um local representativo do clima regional, dispondo-se de mais de 30 anos de coleta de dados diários ininterruptos. O clima da região, conforme MORENO (1961), é o tipo Cfa de Köppen (subtropical úmido sem estação seca definida e com verões quentes).

Utilizaram-se as variáveis meteorológicas diárias de umidade relativa (UR) e de temperatura (T) do ar (9, 15 e 21 horas), a temperatura máxima $\left(T_{\text {max }}\right)$ e mínima $\left(T_{\min }\right)$ do ar, a insolação $(n)$, a precipitação pluvial e a evaporação do evaporímetro de Piche $(E v P)$. As médias diárias de temperatura e umidade relativa do ar foram calculadas com os modelos do Instituto Nacional de Meteorologia para o Rio grande do Sul e, a partir destes, calculou-se a média da pressão parcial de vapor d'água e do déficit de saturação do $\operatorname{ar}(d)$. A temperatura das 15 horas foi utilizada apenas na análise crítica e de consistência dos dados de temperatura máxima e das 21 horas $\left(T_{21}\right)$.

Foram simuladas épocas de semeadura (ES) para os dias 01, 06, 11, 16, 21 e 26 de cada mês, desde agosto a fevereiro, do período de agosto de 1968 a junho de 2002. As ES foram enumeradas em ordem crescente, iniciando em agosto (01) e terminando em fevereiro (42). Foram considerados os seguintes subperíodos da cultura: $S-E$, da semeadura $(S)$ à emergência $(E) ; E-40 \% S T$, da $E$ à $40 \%$ da soma térmica necessária desde a emergência até a antese $(40 \% S T) ; 40 \% S T-A, \operatorname{dos} 40 \% S T$ à antese $(A)$; $A$ - $M L$, da antese à maturação leitosa $(M L)$; e, $M L$ $M F$, da $M L$ à maturação fisiológica $(M F)$.

O solo predominante na região para cultivos de sequeiro pertence à Unidade de Mapeamento São Pedro (BRASIL, 1973) e é classificado como Argissolo Vermelho Distrófico arênico (STRECK et al., 2002). Na definição da capacidade de armazenamento de água disponível no solo (CAD), para o cálculo do $B H$, foi estimado seu incremento ao longo do ciclo do milho em função do aprofundamento simulado do seu sistema radicular. Diante disso, iniciou-se o cálculo do balanço hídrico com $C A D$ 
constante de $17 \mathrm{~mm}\left(C A D_{i}\right)$, para os primeiros $0,10 \mathrm{~m}$ de profundidade do solo, no subperíodo $S$ - E. A máxima profundidade média de $0,60 \mathrm{~m}$ foi adotada a partir da ocorrência da antese, com $112 \mathrm{~mm}$ de $C A D$ final $\left(C A D_{F}\right)$. Os níveis extremos de umidade do solo utilizados no cálculo da $C A D$ foram os obtidos por CARLESSO \& SANTOS (1999). Desde a emergência até a antese, utilizou-se a curva de crescimento do sistema radicular sigmoidal apresentada por DOURADO-NETO et al. (1999), utilizando a fração da soma térmica total (ST) atingida até o dia $n\left(S T_{n}\right)$ em substituição à fração do número de dias, e um fator de forma do crescimento do sistema radicular $(F)$ do milho igual a 0,80 . Neste caso, a fração $S T_{n} . S T^{-1}$, também variou entre os limites de 0,00 a 1,00, conforme exigido pelo modelo.

O balanço hídrico foi calculado para os três grupos de maturação da cultura do milho (superprecoce, $C$, precoce, $P$, e tardio, $T$ ), considerando a soma térmica acumulada como delimitador da duração de cada subperíodo da cultura. As unidades térmicas diárias (UTD) foram determinadas com base nas temperaturas máximas e mínimas diárias limitadas aos extremos de 30 e $10^{\circ} \mathrm{C}$, respectivamente, e temperatura base de $10^{\circ} \mathrm{C}$ (EMBRAPA, 1996). Conforme dados obtidos por NIED (2003), que utilizou dados de ensaios locais de competição de cultivares de milho, para a ocorrência da emergência, consideraram-se 74,1 UTD acumuladas após a semeadura para os três grupos de maturação. A ST média necessária no subperíodo entre a $E-A$, utilizada para os grupos de maturação superprecoce, precoce e tardio, foi de 800,857 e $928 U T D$, respectivamente (NIED, 2003). A partir da antese, utilizou-se um acúmulo de 293 UTD e 835 UTD para estimar a data final do subperíodo com a ocorrência da $M L$ e $M F$, respectivamente, igual para os três grupos de maturação.

Estimou-se a evapotranspiração máxima da cultura $(E T m)$ pela multiplicação do coeficiente de cultura $(K c)$ com os valores de evapotranspiração (ET) calculados com o modelo de Penman (VAREJÃOSILVA, 2000), o qual foi modificado significativamente pelo ajuste na estimativa do saldo de radiação $(R n)$, para corresponder à metodologia de MATZENAUER et al. (2002) no cálculo do $K c$, e por isso considerada apenas como base de cálculo da ETm. Ajustou-se também o termo aerodinâmico ( $E a)$ da equação de Penman (NIED, 2003), devido a grandes períodos de falhas de dados de velocidade do vento. $\mathrm{O}$ ajuste no $E a$ consistiu na substituição do efeito da velocidade do vento a dois metros de altura, pelo efeito da evaporação medida no evaporímetro de Piche (EvP, mm dia-1), resultando (NIED, 2003): $E a=d(0,4205+0,024474 E v P),\left(r^{2}=0,95\right)$, em que $d$ é 0 déficit de saturação de vapor d'água do ar. O ajuste na estimativa do saldo de radiação $(R n)$ consistiu na utilização da metodologia de CUNHA et al. (1989) para a sua estimativa para a cultura do milho. Foi necessário utilizar essa metodologia para determinar $R n$ porque MATZENAUER et al. (2002) estimaram $R n$ para a cultura do milho na determinação da $E T$ ao determinar os valores de Kc para essa cultura em relação a ETm medida em 16 experimentos, realizados em 12 anos, nas condições climáticas do município de Taquari, RS, similares às de Santa Maria, RS. O valor de Rn para a superfície gramada, com uma diferença média em relação à do milho da ordem de -40\% (NIED, 2003), inviabilizaria a utilização desses valores $K c$ consistentes e representativos para a região. A radiação solar global incidente foi estimada pela equação de Ångström-Prescott com coeficientes determinados para Santa Maria por ESTEFANEL et al. (1990).

Nos subperíodos $S$ - $E$ e $A$ - $M L$ utilizaramse os valores médios e constantes do $K c$, específicos por época de semeadura, determinados por MATZENAUER et al. (2002). No transcorrer do subperíodo $E$ - $A$, utilizaram-se funções de terceiro grau para, de acordo com a $E S$, interpolar o valor do Kc em função da fração da soma térmica total atingida até o dia ${ }_{(\mathrm{n})}\left(S T_{n} \cdot S T^{-1}\right)$, tomando-se como valores extremos e um intermediário, os determinados por MATZENAUER et al. (2002) para esse subperíodo. De forma similar, também embasado na soma térmica relativa acumulada, para interpolar os valores diários do Kc no subperíodo da $M L$ - $M F$, utilizaram-se modelos lineares, cujos coeficientes mudaram de acordo com a $E S$. Os modelos de terceiro grau do subperíodo $E-A$, e os lineares para $M L$ - $M F$, tiveram seus coeficientes determinados em função da $E S$, sendo $x$ a fração $S T_{n} . S T$ ${ }^{-1}$. Como exemplo, citam-se os respectivos modelos utilizados para a estimar o Kc diário no decorrer dos subperíodos $E-A$ e $M L M F$, respectivamente, $K c=0,40+0,4422 x+0,8783 x^{2}-0,6704 x^{3}$ e $K c=1,3408-0,8308 x$, válidos para as ES de outubro (NIED, 2003).

Para o cálculo do balanço hídrico $(B H)$ diário foi utilizada a metodologia de THORNTHWAITE \& MATHER (1955), descrita por PEREIRA et al. (1997), com uma adaptação em função do uso da fração $p$ de água disponível igual a 0,4 (BERGAMASCHI et al., 1999). A adaptação consistiu em considerar o início do déficit hídrico quando o armazenamento de água no solo for inferior a $60 \%$ da $C A D$. Para os cálculos, procedeu-se de forma seriada com os dados diários da ETm, precipitação ocorrida entre as $21 \mathrm{~h}$ do dia ${ }_{(\mathrm{n}-1)}$ às $21 \mathrm{~h}$ do dia ${ }_{(\mathrm{n})}$ para o dia ${ }_{(\mathrm{n})}$, capacidade de armazenamento de água $\left(C A D_{(n)}\right)$ no 
$\operatorname{dia}_{(\mathrm{n})}$ e a fração $p$. O ano agrícola foi definido como sendo o período compreendido entre 01/07 do ano " $n$ " e 30/06 do ano "n+1". O roteiro de cálculo do balanço hídrico seqüencial diário seguiu os procedimentos descritos por NIED (2003).

Para a identificação das épocas de semeadura menos sujeitas a deficiências hídricas prejudiciais ao milho, foi avaliada a fração deficitária de água $\left(F D=1\right.$ - ETr.ETm $\left.{ }^{-1}\right)$, no ciclo e nos cinco subperíodos de desenvolvimento. A avaliação dos componentes do balanço hídrico se sucedeu a partir dos valores médios diários e acumulados por época de semeadura no ciclo ou subperíodo. A partir dos valores acumulados da deficiência e $E T m$, no ciclo e nos subperíodos dos $40 \% S T$ - A e $A-M L$, foram calculadas as probabilidades de ocorrência de valores superiores aos níveis $0,10,0,25$ e 0,40 de FD em cada época de semeadura. As probabilidades foram obtidas através da função gama $(\gamma)$, por ser a função de probabilidade que melhor se ajustou aos dados, que para isso foram transformados. A transformação dos dados consistiu na extração da raiz quadrada do módulo do logaritmo neperiano da $F D$, do módulo do logaritmo neperiano da $F D$ ao quadrado e do módulo do logaritmo neperiano da $F D$, no ciclo todo e nos subperíodos dos $40 \% S T-A$ e da $A-M L$, respectivamente. Com os dados transformados, foi efetuado um teste de aderência às probabilidades empíricas cumulativas obtidas, em nível de 5\% e 2\% de probabilidade de erro, com teste unilateral de Kolmogorov-Smirnov (ASSIS et al., 1996; NIED, 2003).

\section{RESULTADOS E DISCUSSÃO}

Na figura 1, é apresentada a média da $F D$ de cada ES, nos diferentes subperíodos de desenvolvimento do milho. Verifica-se que ocorreram diferenças na magnitude da deficiência hídrica nos diversos subperíodos decorrentes da falta ou má distribuição da precipitação.

Da $S$ - $E$ ocorreram as condições hídricas mais favoráveis para o estabelecimento da cultura nas semeaduras de agosto ao final de outubro. Após esse período, ocorrem maiores deficiências de água (Figura 1a). Durante o subperíodo $E-40 \% S T$, as condições de deficiência hídrica apresentam tendência muito próxima daquela da $S-E$. As condições de disponibilidade hídrica nas diferentes épocas de semeadura indicam que, nas $E S$ de novembro a janeiro, as disponibilidades de precipitação são em média insuficientes diante da maior demanda evaporativa da atmosfera nos meses de ocorrência do subperíodo
E - 40\% ST. Esses resultados estão de acordo com os encontrados por BURIOL et al. (1980), que também verificaram os maiores níveis de deficiência hídrica para uma mesma probabilidade de ocorrência nos meses de novembro a março, trabalhando com dados mensais no balanço hídrico seriado para fins climáticos.

No subperíodo $40 \% S T$ - $A$, as semeaduras de meados de setembro a meados de dezembro apresentam as condições menos favoráveis ao atendimento hídrico (Figura 1b). Mas é no subperíodo da $A-M L$ que a deficiência hídrica mais afeta o rendimento de grãos (MATZENAUER et al., 1995; SANTOS \& CARLESSO, 1998; BERGAMASCHI et al., 1999). Dessa forma, as semeaduras realizadas em outubro, em média, apresentaram as maiores deficiências hídricas, seguidas das semeaduras de agosto, setembro, novembro e meses subseqüentes. As ES de agosto e setembro possuem níveis pouco inferiores às de outubro, porém, são ainda elevados. Nesses meses, porém, no subperíodo de $40 \% S T$ - $A$ houve níveis de deficiência bem inferiores aos das $E S$ de outubro. Portanto, as plantas de milho dessas ES estão menos sujeitas a estresse por deficiência hídrica do que as de outubro e novembro. As semeaduras de meados de novembro até o final dezembro apresentaram um decréscimo sensível na deficiência hídrica no subperíodo mais crítico, porém, elevaramse os níveis de deficiência no subperíodo anterior a antese. As deficiências hídricas maiores, associadas às temperaturas elevadas, ocorrendo no subperíodo anterior da antese, segundo MATZENAUER et al. (1995), condicionam a antecipação e o retardamento da emissão das inflorescências masculina e feminina, respectivamente, prejudicando a polinização e reduzindo o número de grãos por espiga. Afora isso e considerando os períodos de ocorrência do subperíodo mais crítico $(A-M L)$, os dados médios apresentados na Figura $1 \mathrm{~b}$ indicam que, em Santa Maria, as semeaduras de milho realizadas de agosto a novembro apresentam as condições menos favoráveis.

$\mathrm{Na}$ figura 2, são apresentadas as probabilidades de ocorrer no ciclo da cultura FD igual ou superior aos níveis 0,10, 0,25 e 0,40, nas diferentes $E S$ e grupos de maturação. Verifica-se que as $E S$ de outubro e novembro são as que apresentaram, nos diferentes níveis, as maiores probabilidades de ocorrer uma fração deficitária superior aos níveis indicados no ciclo todo (Figura 2a). As ES de janeiro e fevereiro, por sua vez, apresentaram as menores probabilidades. Porém, as semeaduras nessas épocas, em geral, deveriam visar mais à produção de fitomassa para alimentação animal, pois, em muitos anos, a soma 


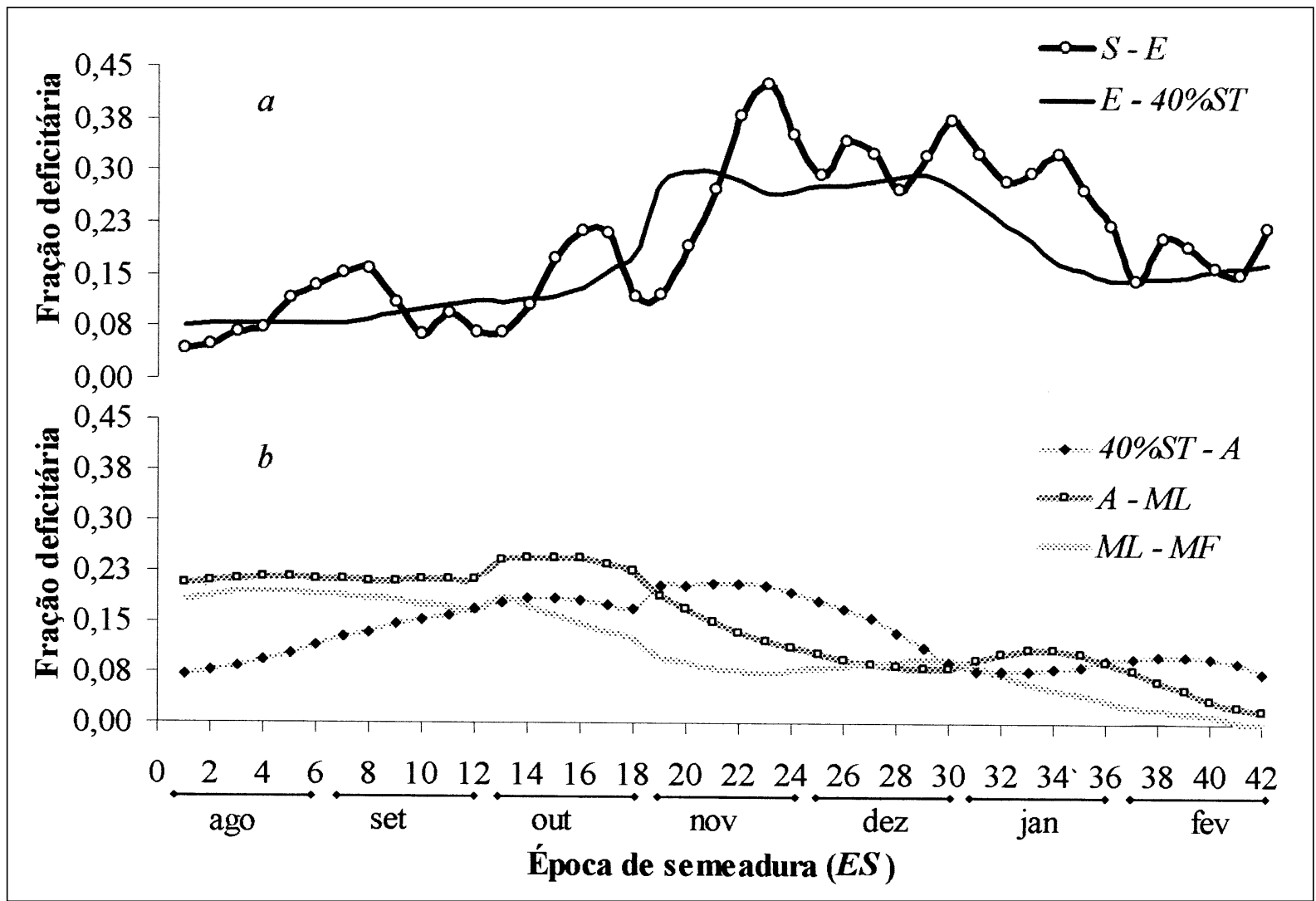

Figura 1 - Valores médios da fração deficitária de água nos subperíodos da semeadura $(S)$ à emergência $(E)$ e de $E$ a $40 \%$ da soma térmica no subperíodo vegetativo (40\%ST), figura $a$, dos $40 \% S T$ à antese $(A)$, de $A$ à maturação leitosa $(M L)$ e da $M L$ à maturação fisiológica (MF), figura $b$, nas diferentes épocas de semeadura do milho. Dados médios dos três grupos de maturação nos 34 anos estudados (1968 a 2002) com as 42 épocas de semeadura simuladas (1/Ago a 26/Fev). Município de Santa Maria, 2003.

térmica é insuficiente para a cultura alcançar a maturação fisiológica, principalmente nas semeaduras após 15 de janeiro.

Uma análise mais detalhada pode ser feita com base nas probabilidades de ocorrência de $F D$ nos subperíodos $40 \% S T$ - A (Figura 2b) e $A-M L$ (Figura 2c), os mais críticos para o milho. No subperíodo de $40 \%$ ST - A, as maiores probabilidades, nos três níveis de $F D$, ocorreram nas épocas de semeadura de 11 de setembro a 15 de dezembro. Nesse período, existem diferenças de até $10 \%$ (1 em cada 10 anos) de probabilidade, conforme o grupo de maturação. Assim, para o grupo de maturação superprecoce, o período mais crítico inicia 10 dias mais tarde. Para o grupo de maturação tardio, a probabilidade foi superior do que para o superprecoce até as semeaduras de 15 de outubro, principalmente nos níveis de deficiência mais acentuados (0,25 e $0,40)$, os quais são mais prejudiciais à cultura. Considerando apenas esse subperíodo de desenvolvimento, as épocas com menor probabilidade de ocorrência de deficiência seriam as de $1^{\circ}$ de agosto até 10 de setembro, principalmente para os genótipos superprecoces, e após 15 ou 20 de dezembro, principalmente para os grupos de maturação tardio e precoce.

O efeito mais drástico de redução de produtividade do milho, devido à deficiência hídrica, ocorre, no entanto, se esta coincidir com o subperíodo A - ML (MATZENAUER et al., 2002). Na figura 2c, verifica-se que há probabilidade relativamente alta de ocorrer deficiência hídrica neste subperíodo quando o milho é semeado até 15 de novembro, principalmente no período de 20 de setembro até o final de outubro. Até 10/09, mesmo com risco significativo, os cultivos com genótipos superprecoces apresentam 1 a $8 \%$ menos probabilidade de ficarem expostos a deficiências hídricas do que os demais. Verifica-se também que, de meados de novembro a meados de dezembro, ocorre uma gradativa e significativa redução da probabilidade de ocorrência dos diferentes níveis de $F D$, ressaltando-se as épocas de semeadura de 


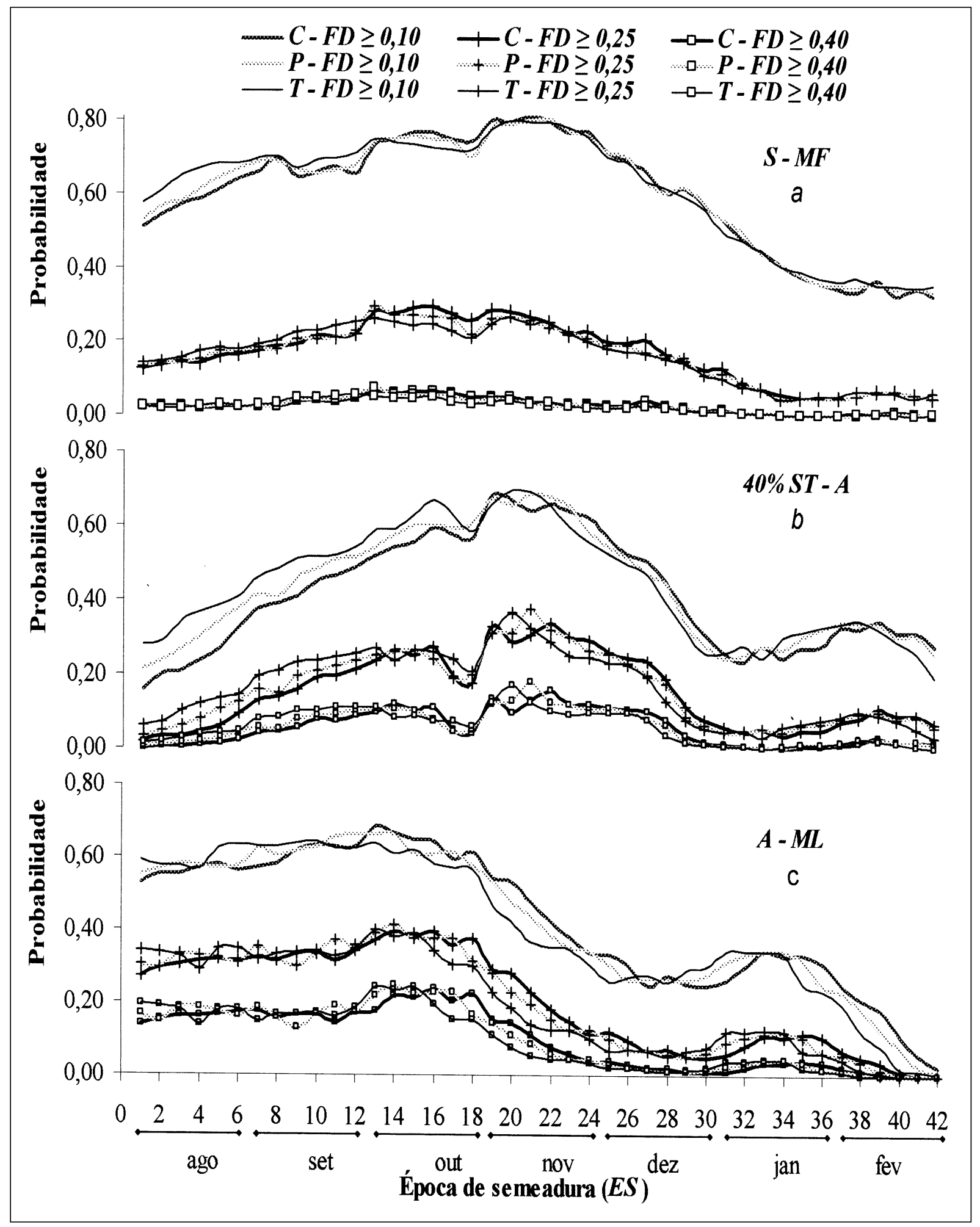

Figura 2 - Probabilidades de ocorrer uma fração deficitária $(F D)$ superior aos níveis $0,10,0,25$ e 0,40 de $F D$, considerando o ciclo todo $(S-M F, a)$, os subperíodos de $40 \%$ da $S T$ do desenvolvimento vegetativo à antese $(40 \% S T-A, b)$ e da antese à maturação leitosa $(A-M L, C)$, para as diferentes épocas de semeadura do milho nos grupos de maturação superprecoce $(C)$, precoce $(P)$ e tardio (T) nos 34 anos estudados (1968 a 2002) e 42 épocas de semeadura (ES) simuladas (1/Ago a 26/Fev). Município de Santa Maria, 2003.

Ciência Rural, v.35, n.5, set-out, 2005. 
dezembro como de menor probabilidade de ocorrência de deficiência hídrica no subperíodo $A-M L$ da cultura do milho.

Considerando-se uma análise conjunta para os dois subperíodos e considerando que o efeito de redução de produtividade do milho é mais drástico se a deficiência hídrica ocorre no subperíodo $A-M L$, pode-se inferir que as melhores épocas de semeadura do milho para Santa Maria, em termos de disponibilidade hídrica, situam-se em dezembro e na primeira quinzena de janeiro, principalmente, desde meados até o final de dezembro. A semeadura nessa época, no entanto, fica condicionada à ocorrência de condições de umidade no solo em nível adequado para a germinação.

\section{CONCLUSÕES}

A maior freqüência de ocorrência de deficiência hídrica, considerando todo o ciclo, ocorre para as épocas de semeadura de início de outubro à primeira quinzena de dezembro, porém as deficiências mais acentuadas ocorrem para as épocas de semeadura de início de outubro à primeira quinzena de novembro. Semeaduras de dezembro à primeira quinzena de janeiro proporcionam os menores riscos de deficiência hídrica no transcorrer dos subperíodos mais críticos no ciclo do milho, havendo condições favoráveis para o estabelecimento da cultura. Considerando todo o ciclo, nas semeaduras de agosto, deve-se dar preferência aos genótipos superprecoces. As épocas de semeadura após meados de dezembro ao início de janeiro são as que apresentam as menores probabilidades de ocorrência de deficiência hídrica em todo o ciclo.

\section{REFERÊNCIAS}

ASSIS, F.N. et al. Aplicações de estatística à climatologia. Teoria e prática. Pelotas: UFPel, 1996. 161p.

BARNI, N.A. et al. Modelo agrometeorológico de predição do rendimento do girassol: II. Ajuste e validação de modelo. Pesquisa Agropecuária Gaúcha, Porto Alegre, v.2, n.1, p.19-31, 1996.

BERGAMASCHI, H. et al. Agrometeorologia aplicada à irrigação. 2.ed. Porto Alegre: UFRGS, 1999. 125p.

BERLATO, M.A. Modelo de relação entre o rendimento de grãos da soja e o défice hídrico para o Estado do Rio Grande do Sul. 1987, 93f. Tese (Doutorado em Meteorologia) - Instituto Nacional de Pesquisas Espaciais.

BERLATO, M.A., FONTANA, D.C. El Niño e la niña: Impactos no clima, na vegetação e na agricultura do
Rio Grande do Sul - aplicações de previsões climáticas na agricultura. Porto Alegre: UFRGS, 2003. 110p.

BRASIL . Levantamento de reconhecimento dos solos do Estado do Rio Grande do Sul. Recife: MA/DPP/DRNR - Divisão de pesquisa Pedológica, 1973. 431p. (Boletim Técnico n.30)

BURIOL, G.A. et al. Disponibilidades hídricas do solo possíveis de ocorrerem no estado do Rio Grande do Sul. Revista do Centro de Ciências Rurais. Santa Maria, v.10 (supl.), p.1$141,1980$.

CARLESSO, R.; SANTOS, R.F. Disponibilidade de água às plantas de milho em solos de diferentes texturas. Revista Brasileira Ciência do Solo, v.23, p.17-25, 1999.

CASEIRO, F.T. et al. Evapotranspiração máxima e coeficiente de cultura do milho (Zea mays L.), no período seco em Santo Antônio do Leverger - MT. Revista Brasileira de Agrometeorologia, Santa Maria, v.5, n.2, p.177-182, 1997.

CUNHA, G.R. et al. Balanço de radiação em cultura de milho In: CONGRESSO BRASILEIRO DE AGROMETEOROLOGIA, 6., 1989, Maceió. Anais... Maceió : INPE, 1989. p.322-327.

DOURADO-NETO, D. et al. Balance hídrico ciclico y secuencial: estimación de almacenamiento de agua en el suelo. Scientia Agrícola, Piracicaba, v.56, n.3, p.537546, 1999.

EMBRAPA. Recomendações técnicas para a cultura do milho. 2.ed. Brasília, Sete Lagoas, MG: EMBRAPA-SPI Centro Nacional de Pesquisa de Milho e Sorgo, 1996. 204p.

ESTEFANEL, V. et al. Insolação e radiação solar em Santa Maria, RS: I - Estimativa da radiação solar global incidente a partir dos dados de insolação. Revista do Centro de Ciências Rurais, Santa Maria, v.20, n.3-4, p.203-218, 1990 .

FERRAUDO, A.S. et al. Modelo agrometeorológico para estimar o rendimento de grãos de milho. Revista Brasileira de Agrometeorologia, Santa Maria, v.3, p.93-96, 1995.

JENSEN, M.E. Water consumptions by agricultural plants. In: KOZLOWSKY, T.T. (Ed). Water deficits and plant growth. New York: Academic, 1968. V.2, p.1-22.

KANG, S. et al. Crop coefficient and ratio of transpiration to evapotranspiration of winter wheat and maize in a semi-humid region. Agricultural Water Management, Amsterdam, v.59, p.239-254, 2003.

MATZENAUER, R. et al. Modelos agrometeorológicos para a estimativa do rendimento do milho, em função da disponibilidade hídrica no Estado do Rio Grande do Sul. Pesquisa Agropecuária Gaúcha, Porto Alegre, v.1, n.2, p.225-241, 1995.

MATZENAUER, R. et al. Consumo de água e disponibilidade hídrica para milho e soja no Rio Grande do Sul. Porto Alegre: FEPAGRO, 2002. 105p. (Boletim FEPAGRO, 10).

MORENO, J.A. Clima do Rio Grande do Sul. Porto Alegre: Secretaria da Agricultura, 1961. 46p. 
NIED, A.H. Balanço hídrico diário do solo simulado para diferentes épocas de semeadura do milho em Santa Maria, RS. 2003. $91 \mathrm{f}$. Dissertação (Mestrado em Agronomia) - Curso de Pósgraduação em Agronomia, Universidade Federal de Santa Maria.

PEREIRA, A. R. et al. Evapo(transpi)ração. Piracicaba: FEALQ, 1997. 183p.

RADIN, B. et al. Estimativa da evapotranspiração da cultura do milho pelo método Penman-Monteith modificado. Revista Brasileira de Agrometeorologia, Santa Maria, v.8, n.2, p.185-191, 2000.
SANTOS, R.F.; CARLESSO, R. Déficit hídrico e os processos morfológicos e fisiológicos das plantas. Revista Brasileira de Engenharia Agrícola e Ambiental, Campina Grande, v.2, n.3, p.287-294, 1998.

STRECK, E.V. et al. Solos do Rio Grande do Sul. Porto Alegre: EMATER/RS/UFRGS, 2002. 141p.

THORTHWAITE, C.W.; MATHER, J.R. The water balance. Publications in Climatology, Centerton, v.3, n.10, p.1104, 1955.

VAREJÃO-SILVA, M.A. Meteorologia e climatologia. Brasília: INMET/ Stilo, 2000. 532p. 